\title{
A gestão da inclusão escolar na rede municipal de São Paulo: algumas considerações sobre 0 Programa Inclui
}

\author{
Anna Augusta Sampaio de Oliveira* \\ Silvana Lucena dos Santos Drago**
}

\section{Resumo}

Para análise da questão da gestão política do processo de inclusão escolar, este artigo aborda o movimento da rede municipal de São Paulo em direção à uma escola inclusiva através da oferta de respostas educativas aos alunos com necessidades educacionais especiais. Assim, descreve o Programa Inclui, em andamento na rede municipal de ensino, que busca organizar, através de projetos, a construção e consolidação de um sistema inclusivo, na perspectiva de estar articulado com as práticas e ações político-pedagógicas que ocorrem desde a educação infantil ao ensino médio e se concentra nas ações necessárias para o atendimento às necessidades educacionais especiais para que se garanta a desejável relação entre educação comum e especial no enfrentamento das dificuldades do processo de ensino e aprendizagem daqueles que precisam de recursos, técnicas, metodologias diferenciadas para que sua trajetória escolar esteja garantida, no cotidiano, assim como está garantida no aspecto legal. Palavras-chave: Inclusão escolar. Ações políticas. Gestão inclusiva. Programa Inclui.

\section{The management of inclusion in the municipal net of schools in São Paulo: some considerations about Programa Inclui Abstract}

To the analysis of issue in political management of the school inclusion process, this article approaches the movement of the Municipal net of schools in São

\footnotetext{
* Pedagoga, Doutora em Educação; Professora da Faculdade de Filosofia e Ciências da Universidade Estadual Paulista Júlio de Mesquita Filho (UNESP). E-mail: hanamel@terra.com.br

** Pedagoga; Professora do ensino fundamental I e Supervisora Escolar da Rede Municipal de Ensino de São Paulo - atualmente - Assessor Técnico responsável pela Diretoria de Orientação Técnica de Educação Especial da SMESP. E-mail:silvanadrago@yahoo.com.br
} 
Paulo towards an inclusive school through the proposal of educational responses for students that have special educational needs. Thus, it is described in the Programa Inclui which is ongoing at the municipal schools. It seeks to organize through projects the construction and consolidation of an inclusive system, and it is aimed at being articulated with the political-pedagogical practices and actions that occur from the kindergarten to high school. They are focused on the required actions to meet special educational needs to ensure that the desirable relationship between common and special education happens. This way, facing the difficulties of teaching and learning to those who need: resources, techniques and differentiated methodologies seeking for their school path guarantee in everyday life, as the legal guarantee.

Keywords: School inclusion. Political action. School management. Programa Inclui

\section{La gestión de inclusion escolar en la red Municipal de São Paulo: algunas} consideraciones a respeto del "Programa Inclui" Resumen

Para el análisis de la cuestión de la gestión política del proceso de inclusión escolar, este artículo aborda el desplazamiento de la red municipal de enseñanza de São Paulo con dirección a una escuela inclusiva a través de la oferta de respuestas educativas a los alumnos con necesidades educacionales especiales. Así, lo describe el Programa Inclui, que está en curso en la red municipal de enseñanza, y busca organizar, a través de proyectos, la construcción y consolidación de un sistema inclusivo, en la perspectiva de estar articulado con las prácticas y acciones político pedagógicas que ocurren desde la educación infantil hasta el bachiller y se concentra en las acciones necesarias para la atención a las necesidades educacionales especiales para que garantice una relación deseable entre la educación común y la especial en el enfrentamiento de las dificultades del proceso de enseñaza y aprendizado de aquellos que necesitan de recursos, técnicas, metodologías diferenciadas para que su trayectoria escolar estea garantizada, en el cotidiano, así como está garantizada en aspecto de la legalidad.

Palavras clave: Inclusión escolar. Acciones políticas. Gestión inclusiva. Programa Inclui.

\section{Introdução}

As experiências vividas pelo mundo nas últimas décadas, frente à evolução da medicina, dos direitos humanos, das ciências sociais, da tecnologia, da comunicação nos aproximaram mais uns dos outros, da diversidade, das diferenças e exige que a escola se apresente como interlocutora do aluno com esse mundo ampliado, que supera barreiras geográficas e que nos obriga a compreender e respeitar as diferen- 
ças, colocando a diversidade como fator preponderante na apropriação de conhecimentos humanizados pelo respeito ao outro. Conforme Jannuzzi (2007).

\begin{abstract}
A justiça de sermos incluídos nos benefícios do progresso, globalizado e enaltecido pelos meios de comunicação, pelas mais diferentes vozes, seja dos representantes poderosos de governos constituídos ou dos homens das ciências de diferentes matizes ideológicos, cada vez mais se centra na educação escolar como força suprema de solução. [...] [o que] pode incitar que se repense a escola com base em outro diálogo, em outra troca de idéias que são possíveis meios geradores de ação.(p.65)
\end{abstract}

Isto poderia nos levar a ilusão de que inauguramos uma nova era educacional, porém, os desafios para operacionalização de novas práticas político-pedagógicas são intensos, pois ainda convivemos com bolsões de miséria, com dificuldades de acesso aos bens culturais e humanos, portanto, assegurar ambientes inclusivos e acolhedores no interior da escola, ultrapassa o limite dela mesma, uma vez que depende, em grande medida, de ações intersetoriais que possam garantir os direitos sociais previstos em lei, mas, muitas vezes, inexistentes nas escolas brasileiras. É a própria Jannuzzi que nos alerta: "há um longo e difícil caminho a ser construído, permeado por um discurso de igualdade, pregado em uma organização mundial cada vez mais excludente" (2007, p.68).

Além dos desafios inerentes à instalação de uma nova lógica educacional, a qual abrange a redefinição de projetos pedagógicos mais afinados com a realidade contemporânea, há, ainda, nos ideários de inclusão escolar, a ênfase na incorporação de alunos com necessidades educacionais especiais ${ }^{1}$ nos espaços comuns de aprendizagem que, embora desejável a longos anos na escola brasileira, na atualidade se reveste de um novo sentido, qual seja: vencer concepções individualistas em relação ao conceito de deficiência, superar velhos paradigmas e compreender as dificuldades específicas das deficiências e dos transtornos globais do desenvolvimento, assim como as altas habilidades como provenientes das interações sociais e não meramente de situações biológicas, orgânicas ou psicológicas. Há a incorporação do papel do outro, ou seja, uma concepção interacionista ${ }^{2}$ na identificação e interpretação das diferenças interpostas pelos quadros de necessidades educacionais especiais.

Sem dúvida estamos diante de uma nova e difícil realidade a ser construída, por isso não é possível, como aponta Góes (2004) simplificar o processo de inclusão

10 conceito de necessidades educacionais especiais será usado neste artigo conforme definição nacional, contida na Política Nacional de Educação Especial na Perspectiva da Inclusão (BRASIL, 2008), que considera três grupos 1) aqueles com deficiência; 2) os com transtornos globais do desenvolvimento e; 3) os com altas habilidades ou superdotados.

20 leitor interessado em compreender as diferentes concepções de deficiência, remeter-se as obras de Omote, S (1996); Oliveira, A.A.S. (2007) 
escolar como se tudo se reduzisse apenas à matrícula daqueles com necessidades educacionais especiais, "ignorando necessidades específicas" (p.72). Oliveira (2006) também afirma que "as escolas, obrigatoriamente, terão que assumir um novo paradigma e uma nova forma de conceber o processo de ensino e aprendizagem e o seu papel frente ao desenvolvimento de todos os alunos" (p.267) e, a autora $(2004 ; 2006 ; 2007)$ ainda insiste que é preciso rever radicalmente os procedimentos escolares, tanto no que se refere à gestão política dos sistemas de ensino, como as práticas no interior da escola. Diz que todo o movimento em direção à uma educação inclusiva nos obriga a.

Uma reflexão profunda das práticas escolares, desde a sua estrutura, organização, planejamento, didática, métodos disciplinas, conteúdos, formas de conhecimento, avaliação, população, etc. Todo o ritual escolar precisa ser revisto. $(2004$, p.79)

Além do movimento interno das escolas, vários autores apontam as dificuldades concretas para a sociedade brasileira frente às "políticas educacionais e os modos de financiamento da educação [...] por isso, a educação para todos ${ }^{3}$ não é uma questão que se refere apenas ao âmbito da educação" (LAPLANE, 2004, p.5). Por outro lado, é preciso que os sistemas de ensino busquem formas de constituição de práticas inclusivas, as quais dependem, em grande medida, das providências político-administrativas geradas no âmbito da gestão pública, seja na esfera nacional, estadual ou municipal. Assim, neste texto, iremos abordar algumas das ações que compõem o Programa Inclui, instituído como política pública municipal pelo Decreto Municipal $n^{\circ}$ 51.778/2010 (SÃO PAULO, 2010), assinado pelo próprio prefeito municipal, de caráter interdisciplinar, em desenvolvimento na rede municipal de ensino de São Paulo.

\section{Notas históricas sobre o movimento municipal}

A Secretaria Municipal de Educação de São Paulo (SME) desde longo tempo atua na direção de atender as peculiaridades dos alunos com necessidades educacionais especiais e desde a criação da primeira escola municipal para Deficientes Auditivos, em 1951, a SME avançou muito no sentido de atender de forma qualificada estes alunos, através de promulgação de leis, decretos, instalação de salas de atendimento, formação de recursos humanos, entre outras providências.

Sigolo, Guerreiro e Cruz (2010) apontam a evolução sobre a publicação de legislações que tratam da educação de pessoas com deficiência, localizando na $2^{\text {a }}$ metade do século XX e $1^{\text {a }}$ década do XXI, um crescimento significativo na produção e elaboração de documentos sobre o direito e as providências para a educação destas pessoas. No entanto, as autoras apontam que ainda "é grande a insatisfação com o

3 Grifos originais do texto, realizados por Laplane. 
atendimento escolar a essa população. Ainda se observa uma distância entre o que acontece no interior das escolas brasileiras e o que as políticas educacionais traçam como metas prioritárias de governo" (p.68). Isto demonstra a necessidade de articulação política entre a legislação e as providências administrativas e orçamentárias que possam garantir no cotidiano o prescrito em lei.

A realidade da $\mathrm{SME}$, em relação à promulgação de leis e da dificuldade de garantir no cotidiano a sua execução não é diferente do que observamos em âmbito nacional, porém, várias ações têm sido realizadas no sentido de uma aproximação entre a lei e o cotidiano, uma vez que as leis parecem impulsionar as ações e o crescimento do atendimento ao aluno com necessidades educacionais especiais nas escolas, através dos serviços de apoio pedagógico.

Este fato pode ser observado com a promulgação do Decreto 33.891 (SÃO PAULO, 1993) que criou, dentre outros serviços, as Salas de Atendimento aos Portadores ${ }^{4}$ de Necessidades Especiais - SAPNES 5 destinadas ao apoio à aprendizagem dos alunos com deficiência, matriculados nas salas de ensino regular ou para 0 atendimento em classe especial daqueles que não se beneficiassem do ensino na classe comum. De 1993 a 2004, foram instaladas 99 salas, sendo que mais da metade destas, ou seja, 46 salas foram instaladas entre 2003 e 2004, demonstrando o movimento da SME em concretizar a proposta de atendimento pedagógico estabelecida pelo Decreto.

Em 18 de outubro de 2004, foi publicado o Decreto Municipal 45.415 (SÃo PAULO, 2004), que estabelece Diretrizes para a Politica de Atendimento a Crianças, Adolescentes, Jovens e Adultos com Necessidades Especiais na rede municipal de ensino abrangendo questões relativas à: sistemática de matrícula; condições para o atendimento da demanda da rede; avaliação pedagógica; definição do público alvo a ser atendido pelos serviços de apoio especializado ${ }^{6}$; organização dos serviços de apoio especializado e acessibilidade.

0 mesmo Decreto define os serviços de apoio especializados que serão oferecidos, sendo eles: Centro de Formação e Acompanhamento à Inclusão (CEFAl); Professor de Apoio e Acompanhamento à Inclusão (PAAI); Sala de Apoio e Acompanhamento à Inclusão (SAAI); Escolas Municipais de Educação Especial (EMEE) e as Instituiç̧ões

\footnotetext{
40 termo portador está citado aqui por estar grafado desta forma no Decreto citado.

5 Prieto (2000) faz um estudo detalhado de todo o movimento do município de São Paulo, em relação ao atendimento aos alunos com necessidades educacionais especiais, no período de 1986 a 1996 . e Sousa e Prieto (2001) apresentam uma caracterização e análise deste atendimento das SAPNEs, na área da deficiência intelectual que também complementam a discussão sobre a instalação deste serviço.

6 Este tem sido um problema recorrente na educação brasileira, ou seja, a definição do público alvo da educação especial, debate que se tornará mais intenso após a promulgação da Lei de Diretrizes e Bases da Educação Nacional - LDB (BRASIL, 1997), que introduz a terminologia necessidades educativas especiais, depois modificada por necessidades educacionais especiais, pelas Diretrizes Nacionais para a Educação Especial na Educação Básica (BRASIL, 2001).
} 
Conveniadas de Educação Especial. Vale atentar para a mudança de denominação das Salas de Atendimento aos Portadores de Necessidades Especiais (SAPNES), para Sala de Apoio e Acompanhamento à Inclusão (SAAI) e a ampliação do atendimento e da atenção à inclusão através do professor itinerante (PAAI) e do centro de formação (CEFAI), certamente uma notável tentativa de garantir na prática o estabelecido nas leis nacionais e na municipal, qual seja, o de atender às especificidades das necessidades educacionais especiais na perspectiva de uma educação inclusiva.

Com a implantação e implementação destes serviços de educação especial ocorreram avanços significativos no período compreendido entre 2005 e 2008, tanto no que se refere à consolidação e ampliação dos serviços, quanto ao aumento na oferta do atendimento educacional especializado aos alunos com necessidades educacionais especiais.

A trajetória em educação especial, na rede municipal de ensino de São Paulo, tem atuado na busca de um crescimento significativo das ações político-administrativas para atender a demanda de alunos com necessidades educacionais especiais e cada vez mais numa perspectiva inclusiva, ou seja, tendo como referência a oferta de serviços de apoio à inclusão, no sentido de mantê-los na classe comum e oferecer subsídio pedagógico ao professor e apoio direto ao aluno. Há avanços importantes na proposta político-educacional da rede municipal de ensino para incorporar os novos princípios provenientes do debate mundial em relação ao lócus de aprendizagem destes alunos, com base nas diretrizes nacionais.

A SME caminha em direção a um amadurecimento e maior direcionamento de ações diferenciais que consolidam a expansão do atendimento especial e uma compreensão mais adequada do próprio conceito de necessidades educacionais especi$a{ }^{7}{ }^{7}$, assim, quando há a publicação da Política Nacional de Educação Especial na Perspectiva da Inclusão, pela Secretaria de Educação Especial (BRASIL, 2008), órgão vinculado ao MEC, a SME de São Paulo já propunha programas específicos para os quadros provenientes das deficiências, dos transtornos globais do desenvolvimento e das altas habilidades/superdotação, em consonância com o estabelecido nacionalmente como público alvo da educação especial.

Com base nas referências nacionais que sustentam cada vez mais o ideário de uma educação inclusiva e dando continuidade a uma trajetória de ações nesta direção de atendimento ao princípio da diversidade, preconizado internacionalmente, em 2009, a SME, através da Portaria 2755/09 (SÃO PAUL0, 2009), instituiu uma equipe intersetorial, com representantes dos diferentes setores da administração pública, designada como Comis-

7 Há um amplo debate sobre esta terminologia através dos Fóruns nacionais, estaduais e municipais, com representantes das universidades, diretorias e secretarias de ensino, professores. Vários autores, nacionais e estrangeiros, tocam nesta discussão e realizam um importante debate sobre o tema. Para citar alguns: Bueno, 1999; Sigolo, Guerreiro e Cruz, 2001; González, 2002; Kassar, 2004; Oliveira, 2006 e os documentos nacionais: BRASIL, 2001; 2008. 
são Especial de Trabalho, para realizar uma avaliação das ações que vêm sendo implantadas ao longo dos anos e, como conseqüência, elaborar um plano de ação, para atender as necessidades educacionais especiais dos alunos da rede municipal de ensino.

Esta comissão, após amplo estudo da rede escolar e mapeamento de suas necessidades, apresenta à Secretaria Municipal de Educação um relatório (SÃO PAULO, 2010) sobre as condições atuais de atendimento as crianças, adolescentes, jovens e adultos matriculados nas escolas municipais, aponta as ações e articulações necessárias para o aprimoramento e alcance das metas da educação especial do Município e propõe adequações normativas em função da legislação nacional em vigor, bem como estratégias a serem utilizadas a curto, médio e longo prazos no âmbito desta Secretaria. Aponta ainda, a necessidade premente do desenvolvimento de ações intersetoriais para assegurar o direito das pessoas com deficiência, na conformidade da legislação em vigor.

Todas estas proposições foram consubstanciadas num programa, denominado Programa Inclui, e que culminou na publicação do Decreto Municipal n 51.778/2010, o qual incorpora os diferentes projetos que definem as ações a serem implantadas ou enriquecidas frente aos desafios do processo inclusivo e institui a Política de Atendimento de Educação Especial, no âmbito da Secretaria Municipal de Educação.

\section{Programa Inclui}

O Programa Inclui apresenta como pressuposto filosófico a democratização qualitativa da educação e a construção de uma escola para todos, o que implica oferecer condições plenas de aprendizagem a todo e qualquer aluno, independentemente de suas condições bio-psico-sociais. Dessa forma, o programa enfatiza o atendimento às necessidades educacionais especiais e, para tanto, após a avaliação das ações necessárias, de forma intersetorial, foram traçadas várias metas com o objetivo de melhoria no atendimento ao aluno com necessidades educacionais especiais.

Essas metas foram organizadas em diferentes projetos, o que permite delinear as ações a serem implementadas e planejar a execução das mesmas, detalhando procedimentos, materiais, cronograma e organizando a exequibilidade de cada um deles. São sete os projetos que compõem o Programa Inclui: 1) projeto Identificar; 2) projeto Apoiar; 3) projeto Formar; 4) projeto Acessibilidade; 5) projeto Rede; 6) projeto Reestruturação das Escolas Especiais; 7) projeto Avaliar ${ }^{8}$.

Ao que parece, o Programa Inclui reúne, nos diferentes projetos, o anseio ou as expectativas pontuadas pela legislação e pela literatura da área, ou seja, atuar em diferentes âmbitos para dar suporte ao processo inclusivo que deve ocorrer no interior das escolas, englobando ações desde a questão da identificação das neces-

8 Neste artigo serão abordados de forma mais específica os seguintes projetos: o Apoiar, o Formar, o Rede e o Avaliar. 
sidades educacionais especiais pela escola, o apoio pedagógico especializado, a formação dos profissionais da educação, a acessibilidade, a constituição de redes de apoio, até a questão da avaliação, tanto do próprio programa, até as especificidades avaliativas das diferentes áreas das necessidades educacionais especiais.

Caiado, Martins e Antonio (2009), com base em pesquisa realizada com professores do ensino comum, das redes pública e privada, relatam que a expectativa dos docentes é que possam ter melhores condições de trabalho nas classes comuns, como "um número menor de alunos, um limite de matrículas de alunos com deficiência por sala, materiais pedagógicos especializados e diversificados em sala de aula, recursos pedagógicos da informática", mas, além destas condições internas, referem-se à necessidade de

[...] salas de recurso na escola para atendimento pedagógico ao aluno com deficiência e apoio ao professor na elaboração de atividades, ações pedagógicas coletivas na escola, presença de um outro adulto em sala de aula - professor assistente, professor ajudante, professor especializado, monitor ou estagiário. [...] adaptações arquitetônicas: [...] formação para todos os profissionais da escola. [...] Afirmam ainda a necessária relação com profissionais da saúde para atendimento ao aluno, aos pais e aos professores. (p.630-631)

Prieto (2007, p. 292), ao entrevistar professores de um centro de apoio, também, com base em seus relatos aponta a necessidade de garantia da "execução de adaptação e criação de materiais e a disponibilização de equipamentos para as escolas, [...] formação permanente [...] e que a Secretaria Municipal de Educação assuma, de fato, o papel de articuladora de todas as ações".

Outros autores ${ }^{9}$ também irão apontar diferentes providências para que o processo inclusivo possa se instaurar no cotidiano das escolas, assim, a proposição de um programa da natureza do Inclui, poderá inaugurar uma proposta articulada entre ações interdisciplinares que possam garantir o atendimento especializado adequado às necessidades educacionais especiais.

No entanto, é preciso apontar que por si só nenhum programa ou nenhuma legislação poderá garantir a execução daquilo que está prescrito em decretos, portarias ou leis, porém, não se pode diminuir a sua importância, uma vez que traça metas, planifica, gerencia e possibilita a concretização das proposições e anseios na direção de uma escola inclusiva que, certamente, adicionados a tantos outros projetos que ocorrem em seu interior, poderão colocar em movimento decisões políticas de melhoria das nossas escolas e, então, exercer o papel fundamental da educação, constituir uma escola democrática e emancipadora.

9 Para citar alguns: Stainback e Stainback, (1999); Oliveira (2008, 2010); Poker (2008); Heredero (2008), Góes e Laplane (2007) e muitos outros. 


\section{Projeto Apoiar}

0 processo de inclusão escolar intensifica a presença do aluno com necessidades educacionais especiais na escola comum do ensino regular e aponta a necessidade da constituição de redes de apoio, que possam proporcionar e viabilizar a aprendizagem escolar e, além disso, oferecer oportunidades significativas nos diferentes contextos de vida deste aluno, como o contexto escolar, familiar, de lazer e nas diferentes atividades sociais. Assim, o apoio pedagógico especializado destaca-se como um componente fundamental na rede de apoio escolar ao aluno com necessidades educacionais especiais.

É recorrente na literatura sobre educação inclusiva, o apontamento da necessidade de apoio a escola, ao professor e ao aluno, para que suas necessidades educacionais especiais sejam atendidas de forma adequada. No entanto, a perspectiva inclusiva traz novos desafios para organização de serviços de apoio, para que se garanta a articulação entre professores das classes comuns e os dos serviços de apoio.

Oliveira e Sigolo (2009) analisam as proposições dos serviços de apoio ao longo dos anos e nas diferentes perspectivas de atendimento na área de educação especial e afirmam que frente à nova política inclusiva a "sala de recursos, concebida como auxílio especial, é um tipo de recurso educacional integrado ao sistema escolar regular" (p. 43), porém em suas conclusões as autoras afirmam que "é preciso mudar a sua concepção de organização" (p. 57), uma vez que a "inclusão de alunos com necessidades educacionais especiais no ambiente escolar, [...] desloca o eixo das dificuldades centradas na criança para as condições que são favoráveis ao sucesso da aprendizagem na sala de aula" (p. 56). Assim, apontam aspectos da maior importância, desde o papel a ser desempenhado pelos serviços de apoio, que seriam, justamente, criar condições para que o processo inclusivo ocorra e para que os alunos sejam mantidos nas classes comuns e, também, a própria concepção de necessidades educacionais especiais, que desloca o eixo da problemática educacional, para as condições oferecidas aos alunos que garantam seu pleno desenvolvimento.

De acordo com a Política Nacional de Educação Inclusiva (BRASIL, 2008), os sistemas de ensino devem oferecer suporte pedagógico especializado ao aluno com necessidades educacionais especiais, atualmente denominado como Atendimento Educacional Especializado (AEE) ${ }^{10}$, o qual caracteriza-se como um importante suporte pedagógico que dará sustentação ao processo de inclusão escolar daqueles com necessidades educacionais especiais, uma vez que além do atendimento direto ao aluno, a análise dos recursos de apoio e a provisão desses recursos, deverão manter uma articulação direta com o professor da classe comum onde o aluno está matriculado.

10 A Secretaria Municipal de Educação oferece atendimento educacional especializado através dos serviços de educação especial, estabelecidos pelo Decreto nº 45.415/2004. 
Com base nessas referências e na própria trajetória da SME do município de São Paulo, o Projeto Apoiar tem como objetivo ampliar o suporte pedagógico especializado para alunos com necessidades educacionais especiais através da instalação de novas salas de apoio e acompanhamento à inclusão (SAAI), ampliação do módulo de professores de atendimento e acompanhamento à inclusão (PAAI), readequação dos Planos de Atuação Pedagógica das Instituições Conveniadas e distribuição de estagiários nas Diretorias Regionais de Ensino.

Dessa forma, a ideia é ampliar as ações de suporte pedagógico especializado e efetivar as seguintes ações: a) a instalação de mais 157 SAAl; b) suprir 100\% das SAAI criadas com recursos humanos, físicos e materiais adequados à demanda a qual se destina; c) readequar a Legislação que trata dos serviços de Educação Especial no Municipio de São Paulo; d) suprir os CEFAl, com no mínimo 06 (seis) PAAI em cada um; e) contratar e acompanhar a distribuição de 1000 (mil) estagiários de pedagogia nas salas de aula, com o intuito de auxiliar o professor da sala regular e/ou dar assistência necessária nos atos de vida escolar (atividades curriculares, educativas, extra-classe entre outras).

Como resultados recentes do Projeto Apoiar, em 2010 foram criadas 133 Salas de Apoio e Acompanhamento á Inclusão (SAAI) e em 2011, 46 salas, ampliando em 179 o número de salas se comparadas com o ano de 2009. A tabela a seguir demonstra o fluxo de instalação de SAAI desde 1993, evidenciando o aumento significativo ocorrido em 2010.

Tabela 1: Fluxo de instalação de SAAI de 1993 a 2011.

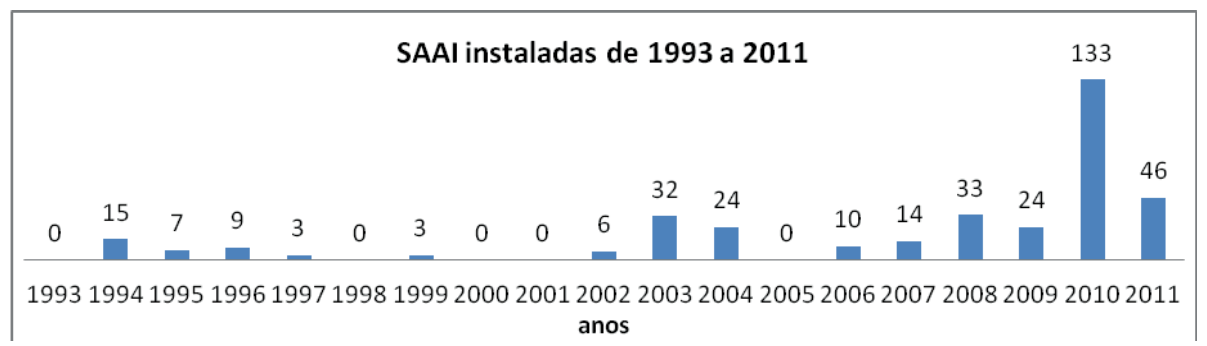

Fonte: Os autores (2012).

Também foram adquiridos materiais específicos às necessidades das demandas das salas, realizadas a designação e distribuição de Professores de Apoio e Acompanhamento á Inclusão (PAAls), nos CEFAls e se alcançou a meta de contratação de 1300 estagiários de Pedagogia para atuar junto aos professores nas salas de aula, além de receberem orientações de toda equipe de Educação Especial de como agir no interior das escolas, ou seja, para que, realmente, sejam apoio à sala de aula e não exclusivamente ao aluno com necessidades educacionais especiais. 
Com esse conjunto de ações há a expectativa de ampliar, agilizar e qualificar o apoio pedagógico especializado oferecendo as condições necessárias para a permanência e acompanhamento da trajetória escolar do aluno com necessidades educacionais especiais.

\section{Projeto Formar}

0 processo de inserção de alunos com necessidades educacionais especiais em classes comuns do ensino regular tem desafiado toda equipe escolar a dar respostas para atender às suas especificidades e particularidades. Para tanto, requer que a equipe assegure procedimentos de gestão que possibilitem identificar as diferenças e a diversidade na sala de aula e, do professor se exige conhecimentos para que possa oferecer respostas pedagógicas adequadas a todos os alunos, incluindo os que apresentam necessidades educacionais especiais. Michels também evidencia a importância do professor neste processo ao dizer que "outro ponto fulcral da reforma educacional em foco está colocado sobre o sujeito que é visto como o elo de ligação dessa política com a sociedade, qual seja, o professor" (2006, p.411).

Vários são os autores ${ }^{11}$ que se debruçam sobre a discussão da formação neste novo contorno da educação brasileira e debatem desde a questão da formação inicial, ou a ausência dela, até a questão da formação continuada, porém, não há dúvidas em relação ao destaque a ser dado à formação de professores para atuarem numa perspectiva inclusiva.

Também há de não se perder de vista os programas de formação continuada, os encontros nos horários coletivos e as reuniões pedagógicas que se constituem como espaços privilegiados e caracterizam a formação permanente dos gestores, dos docentes e do quadro de apoio, uma vez que, se deve buscar de forma sistemática e intencional, problematizar a prática pedagógica cotidiana, a avaliação, o currículo, a organização dos espaços, dos tempos, dos recursos humanos, dos recursos materiais e das ações metodológicas.

No entanto, é necessário que esta seja uma formação permanente e que possibilite o aprofundamento em torno das questões escolares, pois como menciona Michels (2006), o Banco Mundial, em documento de 2005, ressaltava " que a formação em serviço é uma estratégia eficaz para melhorar o conhecimento dos professores", mas mantinha uma visão, economicista sobre a formação, uma vez que apontava, conforme cita Michels (2006, p. 412), que " principalmente,[a formação em serviço] diminui o custo dessa preparação.", ou seja, a formação continuada em serviço, não pode significar meros encontros entre professores, mas sim, ir em busca de uma interlocução que considere a troca de experiências entre os pares da escola ou de seu entorno, mas também, considerem a necessidade de interlocutores qualificados que possam

11 Para citar alguns: Denari (2004, 2006), Ferreira (2004), Martins (2009), Mendes (2009), Pires (2009), Prieto (2007, 2009), Oliveira (2009, 2010). 
contribuir no avanço teórico-metodológico da escola, na tentativa de constituir novos contornos à organização escolar e à prática pedagógica.

Assim, o Projeto Formar tem o objetivo de proporcionar a formação permanente de toda equipe escolar, através de cursos de formação continuada em diferentes dimensões como cursos de aperfeiçoamento, extensão e especialização para aprimoramento de toda equipe pedagógica e dos professores especializados, além de assessorias específicas para elaboração e aplicação de referenciais de avaliação no Ensino Fundamental, formação nas áreas específicas da deficiência, dos transtornos globais do desenvolvimento e altas habilidades/superdotação e capacitação específica na formação geral realizada pela Educação Infantil, Ensino Fundamental e Ensino de Jovens e Adultos, entre outras providências formativas, como o próprio espaço dos horários coletivos no interior das escolas.

No que se refere à formação foram pensados 4 grandes eixos: 1) formação para os professores que atuarão nos serviços de Educação Especial (cursos de especialização); 2) formação continuada para os professores que atuam nos serviços de Educação Especial; 3) curso de capacitação para educadores e quadro de apoio; e 4) formação permanente de toda equipe escolar, nos horários coletivos no interior de cada escola.

0 Projeto Formar tem sido prioridade para a SME e como resultados preliminares podemos apontar a formação em nível de pós-graduação Lato Sensu, em Curso de Especialização na área da Educação Especial, através de convênio com a Faculdade de Filosofia e Ciências, UNESP, campus de Marília, desde 2007. Na primeira e segunda edições do curso foi concretizada a formação de 200 professores, na área de deficiência intelectual, física, a auditiva e na área de deficiência visual. Na $3^{a}$ edição foram contempladas as áreas da deficiência auditiva (surdez) e da intelectual e na $4^{\mathrm{a}}$, em andamento até outubro de 2012, somente a área da deficiência intelectual, devido à demanda do próprio sistema. Em 2012, também foi estabelecida uma pareceria com o Mackenzie para formação na área da surdez. Dessa forma, foram formados 700 professores para atuação nos serviços de educação especial do município, cumprindo uma importante meta de formação especializada para atender as necessidades da rede.

Além da formação em nível de pós-graduação, a rede de ensino investiu em capacitações da equipe de educação especial, uma abordagem de formação piramidal, os professores recebem formação e são multiplicadores em suas regiões e escolas. Em 2009, foram organizados 4 grupos de 49 componentes e mais a participação da equipe da Diretoria de Orientações Técnicas - Educação Especial (DOT-EE), perfazendo um total de 55 participantes por grupo, sendo 40 professores regentes das salas de apoio e acompanhamento à inclusão (SAAIS), 7 Professores de Apoio e Acompanhamento à Inclusão (PAAI), 2 coordenadores do Centro de Formação e Acompanhamento à Inclusão (CEFAI) e 6 componentes da Diretoria de Orientações 
Técnicas de Educação Especial (DOT-EE). Os encontros presenciais ocorreram na Secretaria Municipal de Educação, no período de maio a dezembro de 2009. Das 128 horas, 96 foram presenciais e 32 horas à distância, através do atendimento e orientações on-line aos professores vinculados ao curso. Também foram desenvolvidas 120 horas de monitoramento e gerenciamento de dados de avaliação provenientes do Referencial de Avaliação da Aprendizagem na Área da Deficiência Intelectual (RAADI). Nesse processo de formação nas escolas e nas Diretorias Regionais de Educação, foram envolvidos aproximadamente 1200 professores, de 235 escolas do ciclo 1 do Ensino Fundamental

Em 2010 foi mantida a abordagem de formação piramidal com a participação de 196 professores especialistas da Rede Municipal de Ensino de São Paulo e 6 componentes da equipe da Diretoria de Orientações Técnicas - Educação Especial - DOT-EE, perfazendo um total de 202 participantes. Para execução do projeto foram envolvidas as 13 regiões educacionais de São Paulo e 240 escolas do Ensino fundamental - ciclo I. No que se refere às atividades de formação, cada grupo recebeu 24 horas de curso presencial e em relação à assessoria pedagógica, contou com 64 horas de atividades, sendo 32 horas presenciais de acompanhamento do processo de formação e 32 horas de atividades online, perfazendo um total de 88 horas de formação para cada grupo.

Em 2011 foram empreendidas três ações, a saber: 1)acompanhamento da aplicação do RAADI I; 2)elaboração, formação e aplicação do Referencial de Avaliação do Ciclo 2 do Ensino Fundamental; e 3)revisão do Referencial de Avaliação para o EJA e CIEJA. Em outubro e novembro de 2011 foram realizados em todas as regiões concomitante, os Seminários Regionais de Formação para implantação e implementação do Referencial de Avaliação da Aprendizagem na Área da Deficiência Intelectual, do ciclo 2 do Ensino Fundamental e Educação de Jovens e Adultos.

Estes Seminários tinham como objetivo a formação dos Coordenadores Pedagógicos que atuam no ciclo II e EJA, Professores representantes do Ensino Fundamental II , EJA/CIEJA e Regentes de SAAI das Unidades Educacionais da RME, a fim de oferecer indicativos para uma avaliação e acompanhamento da aprendizagem do estudante com deficiência intelectual do Ciclo II do Ensino Fundamental e da EJA, participaram desta ação 1467 educadores..

Em 2012 mantém a proposta de formação para a implementação do Referencial sobre Avaliação de Aprendizagem na área da Deficiência Intelectual (RAADI), com o objetivo de consolidar o RAADI como instrumento de avaliação dos alunos com deficiência intelectual - DI da rede municipal de ensino compondo a rotina de avaliação nas escolas envolvendo a gestão escolar e os professores das escolas na avaliação através da orientação dos Professores de Apoio e Acompanhamento à Inclusão (PAAl) e dos Professores Regentes de Sala de Apoio e Acompanhamento à Inclusão (SAAl) em suas regiões. 
Além destas formações especificas nas áreas da deficiência intelectual, todos os anos são oferecidos cursos em todas as áreas da deficiência, TGD, comunicação suplementar ou alternativa, soroban, braile, LIBRAS etc. Também foram produzidos documentos e DVDs para realizar a formação das equipes escolares e dos pais. Os materiais estão disponíveis para download no Portal da Educação: www.portalsme.prefeitura.sp.gov.br.

A Prefeitura de São Paulo publicou um decreto que determina a liberação na internet, para download livre e gratuito, de todos os materiais didáticos produzidos pela Secretaria Municipal de Educação.

Também é realizada formação permanente de toda equipe escolar, nos horários coletivos no interior de cada escola, em palestras e cursos optativos. 0 público-alvo são gestores, equipe docente, equipe do quadro de apoio e têm sido beneficiados anualmente 5000 profissionais que atuam nas unidades educacionais da rede municipal de ensino e 680 professores especialistas na área da educação especial.

\section{Projeto Rede}

Reconhecer o direito das pessoas com deficiência à educação significa assegurar um sistema educacional inclusivo em todos os níveis, bem como o aprendizado ao longo de toda a vida, assim, dentre outros objetivos, garantir que as pessoas com necessidades educacionais especiais não sejam excluídas da escolarização e que recebam o apoio necessário, com vistas a garantir sua trajetória escolar, bem como sejam efetivadas medidas individualizadas de apoio adotadas em ambientes que maximizem o desenvolvimento acadêmico e social, compatível com a meta de inclusão escolar e uma articulação com a área da saúde.

Pacheco e outros (2007) ao relatarem experiências e estudos sobre inclusão escolar da Austria, Islândia, Portugal e da Espanha, comentam o papel exercido pelos serviços de apoio assim como as novas reflexões que foram suscitadas frente à suas abordagens na perspectiva da inclusão escolar. Os autores afirmam que "o papel dos especialistas externos parece estar se afastando da abordagem clínica em direção a uma classe colaborativa total e a soluções escolares totais" (PACHECO et al. 2007, p.69). Há, ainda, outros pontos evidenciados pelos autores, para nós importa ressaltar que:

Todos os relatórios destacaram a importância da participação dos serviços de apoio antes do início da educação escolar. Em muitos casos, esses serviços foram aqueles que informaram às escolas sobre os alunos que necessitavam de atenção especial quando freqüentassem a escola. (p.68)

0 objetivo geral do Projeto Rede é, justamente, oferecer apoio no cuidado aos alunos matriculados nas unidades educacionais com quadros de deficiências e trans- 
torno global do desenvolvimento, que necessitem de apoio intensivo para participação nas atividades escolares com assistência necessária nos atos de vida cotidiana (mobilidade, auxílio na questão da higiene, alimentação, medicamento, recreio, atividades dentro e fora das salas) e outras que se fizerem necessárias para participação ativa do aluno na rotina escolar e aquelas extra-curriculares realizadas pela escola.

Para tanto, não basta apenas colocar um cuidador, mas articular diferentes ações que garantam o teor e a qualidade de sua atuação na escola. Assim, o projeto tem caráter interdisciplinar e conta com uma equipe de suporte da área da saúde, afinada com o ideário de inclusão escolar, que deverá contribuir na identificação das especificidades de alguns quadros de necessidades educacionais especiais, avaliação da funcionalidade dos alunos, orientação e prescrição de adequações dos materiais escolares ou do mobiliário, orientação à escola e a família e, também, atuará na formação dos Auxiliares de Vida Escolar, orientandoos sobre aspectos relacionados a posicionamento e deslocamento do aluno, niveis de sucção e deglutição alimentar, formas adequadas para troca e higienização, entre outras ações.

As experiências relatadas por Pacheco e outros (2007, p.69), em relação à atuação dos serviços de apoio, apontaram que:

Houve variação no quanto os serviços intervieram $\mathrm{cm}$ relação aos alunos que já estavam na escola. Geralmente, dependeu da complexidade das necessidades dos alunos e de quão confiantes e capazes os professores eram. As principais tarefas referiam-se à identificação de necessidades, avaliação do progresso, monitoramento, assistência para resolução de problemas e consultoria e treinamento de pessoal de ensino.

Assim, o projeto Rede se caracteriza como uma proposta inovadora da SME e afinada com experiências em países desenvolvidos, na tentativa de responder às necessidades educacionais especiais que necessitam de apoio intensivo e, para isto, contará com o apoio da saúde, mas com uma visão educacional, ou seja, a busca de alternativas de toda ordem para manter o aluno em situação comum de aprendizagem.

Para sua exequibilidade são realizadas várias ações, a) prestação de serviços de apoio, a ser denominado Auxiliar de Vida Escolar (AVE) a fim de oferecer apoio aos alunos que necessitem deste atendimento direto e particularizado; b) suporte técnico às equipes escolares; c) avaliação Funcional dos alunos e indicações para os recursos de tecnologia assistiva; d) regulação com os serviços de saúde; e) assessorar as escolas para a indicação de tecnologia assistiva com o objetivo de eliminar as barreiras de acesso ao currículo e à comunicação; f) produção de materiais orientadores para Pais e Professores sobre as necessidades educacionais especiais; e g) formação dos profissionais da escola e dos pais. 
0 Projeto Rede visa atender aqueles que apresentem quadros de deficiências e transtorno global do desenvolvimento, proporcionando a permanência e acompanhamento de alunos que não apresentam autonomia para a participação em todo o processo de escolarização e colaborar com a escola na identificação e acompanhamento de alunos com superdotação/altas habilidades. Desta forma procura responder a uma demanda escolar que necessita de apoio específico, que não apenas escolar ou curricular, para que se garanta sua permanência na escola e sua aprendizagem escolar.

O Projeto Rede em implantação em 2010, atuou em 3 importantes frentes de ações: 1) Implantação do quadro de profissional do Auxiliar de Vida Escola ( AVE), com contratação de 500 profissionais em 2011 e ampliação de mais 213 em 2012, perfazendo o total de 713 AVE, que são aqueles profissionais que atuam na escola com alunos com deficiência e TGD, cujos comprometimentos impossibilitem as atividades de higiene, locomoção e alimentação ;2) implantação dos supervisores técnicos (Fisioterapeutas e Terapeutas Ocupacionais), com a contratação de 21 Fisioterapeutas e 21 Terapeutas Ocupacionais, totalizando 42 Supervisores Técnicos, com o objetivo de supervisão e acompanhamento das atividades desenvolvidas pelo AVE e; 3) constituição do quadro de profissionais do Núcleo Multidisciplinar (NMD). Os NMD atuam em conjunto com o CEFAl uma vez por semana em cada DRE - médico fisiatra, psiquiatra, psicólogo, fonoaudiólogo, assistente social, enfermeiro e nutricionista.

A implantação do projeto em 2010 e 2011 levantou que 76\% alunos vieram encaminhados por problemas comportamentais ou de comunicação e 67\% dos alunos encaminhados para a avaliação necessitavam de abordagem com fonoaudiologia e psicologia, sendo que apenas $12 \%$ de total dos alunos encaminhados necessitavam de atendimento médico. Tendo em vista esta constatação, foram realizadas reuniões com as equipes dos CEFAls e Sociedade Paulista para o Desenvolvimento da Medicina (SPDM) - responsável pelo acompanhamento e formação da equipe -, em março de 2012, com o objetivo de avaliar as ações desenvolvidas pelo Núcleo Multidisciplinar (NMD) frente às necessidades apresentadas pelas unidades educacionais em relação ao atendimento dos alunos encaminhados. Após a análise foi sugerido em comum acordo entre as equipes dos CEFAI, DOTEE e SPDM, um novo modelo de funcionamento do NMD, estruturado por alocação fixa de 1 psicóloga, 1 fonoaudióloga e 1 assistente social em cada DRE/CEFAl, visando o desenvolvimento de atividades que melhor atendam o aluno, a família e a equipe escolar. Nesse sentido, essa proposta culminará em substituir a equipe atual dos Núcleos Multidisciplinares (NMD) por 13 psicólogas, 13 fonoaudiólogas e 13 assistentes sociais, que terão a carga horária de 20 horas semanais, sendo esta distribuída entre os períodos da manhã e tarde.

\section{Projeto Avaliar}

A avaliação caracteriza-se como um importante componente na implantação e implementação de novos programas educacionais. É evidente a necessidade de acompanhamento das ações, a análise de sua implementação e a avaliação de todo o processo, com o objetivo de identificar fragilidades ou incorreções na aplicação dos 
programas. A avaliação nos permite o contínuo e permanente processo de ajuste, re-organização e de retro-alimentação de todo o programa.

Dessa forma, o Projeto Avaliar, apresenta dois eixos de ação: (a) avaliação e monitoramento do impacto da implantação e implementação de todos os projetos que compõem o Programa Inclui; (b) e a avaliação e acompanhamento dos processos de aprendizagem dos alunos, público alvo da Educação Especial.

No que se refere a ação 1, de avaliação e monitoramento do Programa Inclui, a proposta é a definição de indicadores avaliativos que permitam analisar as diferentes ações propostas, suas formas de implantação e implementação e seu impacto na melhoria da condição de aprendizagem dos alunos com necessidades educacionais especiais, uma vez que todas as ações foram delineadas como formas de apoio a sua escolarização e a melhoria das condições escolares que propiciem acesso e permanência destes alunos, com 0 objetivo de garantir sua trajetória escolar e sua plena inserção no ambiente escolar.

Está, então, em definição um protocolo de avaliação, disponibilizado on-line, no Portal da Secretaria, para que todos os profissionais das escolas possam ter acesso e responder os indicadores diretamente no Portal e, através de programação computacional, organizar e tabular os dados através de gráficos e tabelas, para que a equipe de educação especial realize a análise dos indicadores para avaliar a implantação dos diferentes programas em andamento nas escolas. Esse é um sistema que permite a participação de todos e, ao mesmo tempo, permite a SME o monitoramento dos programas educacionais, para avaliar se as políticas de gestão para constituição de um sistema inclusivo que estão em aplicação nas escolas, diminuindo a distância entre a legislação e o cotidiano das escolas.

A avaliação institucional do Programa Inclui e de seus diferentes projetos permite a SME realizar ajustes, ampliação, adequações nas propostas de forma mais ágil e em sintonia com a expectativa estabelecida na gestão educacional e no saudável ajuste entre a política educacional e as escolas, como lembra Michels (2006, p. 408), "é no embate entre a proposição política e o cotidiano da escola que esta vai constituindo-se e organizando-se." .

A ação 2 refere-se a avaliação e acompanhamento da aprendizagem. A avaliação da aprendizagem tem sido tema de grandes controvérsias e dificuldades na educação brasileira e, torna-se uma dificuldade suplementar quando o foco da avaliação é a aprendizagem do aluno com deficiência intelectual (KASSAR, 2007; OLIVEIRA, 2011; PADILHA, 2006, 2007; PLETSCH, 2009).

Por outro lado, a avaliação caracteriza-se como um elemento fundamental para subsidiar a aprendizagem e assessorar o acompanhamento da escolarização desse aluno nas classes comuns, pois poderá indicar os recursos necessários para viabilizar o seu sucesso 
educacional. Cabe a escola a preocupação em adequar os diferentes instrumentos de avaliação para que possam permitir também a avaliação desses alunos, de modo a conhecer o que o aluno aprendeu, a analisar as variáveis implícitas no processo de ensino e de aprendizagem. No dizer de Oliveira (2011, p.14), "deve ser garantida a aprendizagem e a escolarização, o que nos remete a preocupação com o currículo e as possibilidades a serem oferecidas a eles para que possam avançar no conhecimento escolar".

As estratégias de avaliação também deverão permitir avaliar as suas necessidades curriculares e pedagógicas específicas e os apoios necessários para que possa se garantir a sua aprendizagem, com base nos objetivos educacionais, mesmo que com adequações.

Assim, é preciso acompanhar seu processo de avaliação através das provas institucionais, mas, também, o estabelecimento de critérios específicos relacionadas às diferentes especificidades das áreas das necessidades educacionais especiais e a utilização do Referencial de Avaliação da Aprendizagem na área da Deficiência Intelectual - RAADI -, proposto pela rede municipal de educação (SÃO PAULO, 2008).

Após a elaboração desse referencial - o RAADI - em 2008 foi realizado um projeto piloto (OLIVEIRA, 2010a) e nos anos de 2009 e 2010, aplicação do material nas escolas da rede municipal de ensino, através da avaliação realizada pelo professor da classe comum, com formação e orientação do professor especialista. Foram realizadas 4 avaliações, sendo que em 2009 foram avaliados 1174 alunos numa $1^{\circ}$ avaliação e, em 2010, 2322 alunos foram avaliados do $2^{\mathrm{a}}$ ao $5^{\circ}$ ano do Ensino Fundamental. A avaliação se deu nas áreas de Língua Portuguesa, Matemática e Ciências e Natureza. Também, como proposta e princípio de avaliação na perspectiva da inclusão foi realizada uma avaliação descritiva da Instituição escolar e da sala de aula.

Os dados preliminares da análise relativa à aprendizagem do aluno com deficiência intelectual na área da Língua Portuguesa relacionados ao $1^{\circ}$ semestre de $2009^{12}$, apontam que foram avaliados 1.174 alunos, distribuídos entre os $2^{\circ}$ e $5^{\circ}$ anos do Ensino Fundamental - Ciclo I, sendo $19 \%$ do $2^{\circ}$ ano, 22\% do $3^{\circ}, 23 \%$ do $4^{\circ}$ e $36 \%$ do $5^{\circ}$ ano, onde há maior incidência de alunos (36\%), o que demonstra a evolução da trajetória escolar de alunos com deficiência intelectual e, por outro lado, pode sugerir que os mesmos permanecem neste ano escolar por mais tempo, embora os dados, neste momento, ainda não permitam realizar esta afirmação.

Podemos observar, pelos dados apresentados, que o aluno com deficiência intelectual de todos os anos escolares, possuem melhor desempenho em leitura, do que em

12 Vale ressaltar a continuidade da utilização do RAADI, sendo que, no momento, já contamos com dados de quatro avaliações, dos $1^{\circ}$ e $2^{\circ}$ semestres de 2009 e 2010, que ainda estão em análise e já foram envolvidas 342 escolas e 2322 alunos. 
escrita e melhor desempenho parcial, do que satisfatório. Valentim (2011), em pesquisa utilizando também o RAADI, numa cidade do interior paulista e com menor número de alunos, também encontra melhores condições dos alunos em leitura do que em escrita.

Outro ponto importante, que merece destaque, e foi observado nos dados desta pesquisa, é que os índices de aprendizagem, tanto da leitura quanto da escrita, melhoram quando é exercida uma aprendizagem colaborativa, ou seja, quando os alunos com deficiência intelectual recebem colaboração de um colega mais experiente ou do professor para a realização da atividade.

Valentin (2011, p. 113) em pesquisa sobre avaliação escolar do aluno com deficiência intelectual, após a aplicação monitorada do Referencial de Avaliação da Aprendizagem na área da Deficiência Intelectual, conclui que:

[...] a avaliação da aprendizagem do aluno com DI, que tem-se mostrado, entre tantos outros, um nó na educação, precisa ser desatado para que a inclusão escolar se transforme em prática efetiva. A escola, enquanto espaço da diversidade, da heterogeneidade, deve ter como ação imediata a substituição de práticas avaliativas restritas e estáticas por práticas que respondam às especificidades do aluno com deficiência - algumas delas citadas em nosso trabalho - e, dessa forma, oferecer a esses alunos a oportunidade de máxima aprendizagem, de inserção na sociedade, em igualdade de condições educativas.

Como pudemos observar na descrição do Programa Inclui, as ações são bem abrangentes e buscam atuação em diferentes âmbitos: matrícula e permanência na escola, caracterização da demanda de alunos com necessidades educacionais especiais, garantia do atendimento educacional especializado, formação de professores em diferentes modalidades (cursos de extensão, aperfeiçoamento, especialização, assessorias) e nos diferentes níveis de ensino (infantil, fundamental, jovens e adultos), formação de auxiliares de vida escolar e de pais e, sem descuidar de necessidades educacionais especiais que exigem apoio intensivo, como prevê o Projeto Rede.

De acordo com Oliveira e Leite (2007):

concretizar a ideia de um sistema educacional inclusivo exige um planejamento bastante complexo, que engloba desde as ações a serem implementadas no macro sistema, a partir da elaboração de uma política educacional diferenciada, até as ações pontuais no cotidiano da sala de aula, através de um planejamento pedagógico que atenda à diversidade dos alunos presentes na escola, inclusive daqueles com deficiência. 
Todas as ações previstas no Programa Inclui se apresentam articuladas e uma dará sustentação à outra e todas juntas poderão garantir uma escola cada vez mais atenta às necessidades de seus alunos e, portanto, inclusiva e democrática, como prevê as leis que regem o Estado Brasileiro.

\section{Algumas considerações}

No entanto, apesar das diretrizes nacionais que apontam os caminhos para práticas inclusivas, há diferenças profundas na forma como os sistemas educacionais compreendem o significado da proposta de inclusão escolar e, consequentemente, na forma como incorporam esse novo paradigma na prática cotidiana, seja na instância administrativa, formativa, organizacional ou pedagógica.

0 município de São Paulo, maior município da federação, tem atuado fortemente no delineamento de políticas públicas inclusivas e implementado várias ações para que a garantia legal de uma escola aberta à diversidade, que lide com a diferença em todas suas dimensões e atenda às necessidades educacionais especiais realmente se concretize no cotidiano das escolas. Essa não é uma tarefa simples, ao contrário, reveste-se de grande complexidade e exige ações nos diferentes âmbitos que compõem o sistema educacional e, além disso, ações que extrapolam a educação, incorporando uma visão interdisciplinar do processo educativo e expandindo as ações da educação em parcerias intersetoriais, convênios interinstitucionais e colaboração de outras instâncias sociais, como a Universidade, por exemplo.

O Programa Inclui busca organizar, através de projetos, a construção e consolidação de um sistema educacional inclusivo. Assim, na perspectiva de estar articulado com as práticas e ações político-pedagógicas que ocorrem desde a educação infantil ao ensino médio se concentra nas ações necessárias para 0 atendimento às necessidades educacionais especiais para que se garanta a desejável relação entre educação comum e especial no enfrentamento das dificuldades do processo de ensino e aprendizagem daqueles que precisam de recursos, técnicas, metodologias diferenciadas para que sua trajetória escolar esteja garantida, no cotidiano, assim como está garantida no aspecto legal. Então, se busca uma convergência entre aquilo que se anuncia enquanto princípio teórico e legal com o que acontece no cotidiano da escola.

No dizer de Oliveira e Leite (2007, p.514), "o êxito da educação inclusiva dependerá, em grande medida, da oferta de uma rede de apoio à escola, através do trabalho de orientação, assessoria e acompanhamento do processo de inclusão". E é isso que se pretende avançar com a elaboração e aplicação do Programa Inclui, o qual já apresenta impacto importante na rede de ensino e que 
culminou no Decreto n 51.778/11 (SÃO PAULO, 2011) que institui o compromisso político na constituição das escolas inclusivas.

A proposta de inclusão escolar traz implicações aos sistemas educacionais e aponta a necessidade de transformações abrangentes nos âmbitos político, administrativo e pedagógico. Alcançar as metas de um sistema educacional inclusivo exige o planejamento e execução de ações de grande porte, responsabilidade da instância político-administrativa. É o que podemos observar na intenção da Secretaria Municipal de Educação, do município de São Paulo, através da execução do Programa Inclui.

\section{Referências}

BRASIL. Lei no 9.394, de 20 de dezembro de 1996. Estabelece as Diretrizes e Bases da Educação Nacional. Diário Oficial [da] República Federativa do Brasil. Brasília, DF, 23 dez. 1996.

. Ministério da Educação. Diretrizes Nacionais para a Educação Especial na Educação Básica. Conselho Nacional de Educação (CNE). Brasília, 2001.

. Ministério da Educação. Secretaria de Educação Especial. Diretrizes operacionais da Educação Especial para o Atendimento Educacional Especializado naEducação Básica. Brasília: MEC/SEESP, 2008.

BEYER, O. H. A Educação Inclusiva: incompletudes escolares e perspectivas de ação. Cadernos de Educação Especial, [Rio Grande do Sul], n. 22, 2003.

BUENO. J. G. S. Crianças com necessidades educativas especiais, política educacional e a formação de professores: generalistas ou especialistas?. Revista Brasileira de Educação Especial, Marília, SP, v. 3, n. 5, p.7-25, set. 1999. Disponível em: <http:// educa.fcc.org.br/pdf/rbee/v03n05/v03n05a02.pdf>. Acesso em: 05 set. 2012.

CAIADO, K. R. M.; MARTINS, L. de S.; ANTONIO, N. D. R. A Educação Especial em Escolas Regulares: tramas e dramas do cotidiano escolar. Rev. Dialogo Educ., Curitiba, v. 9, n. 28, p. 621-632, set. /dez. 2009. Disponivel em: <http://www2.pucpr.br/reol/ index.php/DIALOGO?dd1=2837\&tdd99=view>. Acesso em: 05 set. 2012.

DENARI, F. E. Um (novo) olhar sobre a formaç̧ão de educação especial: da segregação à inclusão. In: RODRIGUES, David (Org.). Inclusão e Educação: doze olhares sobre a educação inclusiva. São Paulo: Summus, 2006. p. 35-63. 
Formação de professores em Educação Especial: a ótica do GTEE-06 e do Fórum Permanente de Educação Especial. In: OMOTE, Sadao (Org.) Inclusão: intenção e realidade. Marília: Fundepe, 2004. p. 61-76.

FERREIRA, M. C. C. Formação de Professores. In: MENDES, E. G.; ALMEIDA, M. A.; WILLIANS, L. C. A. (Orgs.) Temas em Educação Especial: avanços recentes. São Carlos: Ed. UFSCar, 2004. p. 251-256.

GONZÁLEZ, J. A. T. Educação e diversidade: bases didáticas e organizativas. Porto Alegre: ArtMed, 2002. 280 p.

JANNUZZI, G. de M. Escola e Inclusão: é possivel o diálogo? In: TUNES, Elizabeth; BARTHOLO, Roberto (Orgs.). Nos limites da ação: preconceito, inclusão e deficiência. São Carlos: EDUFSCAR, 2007. p. 59-68.

KASSAR, M. C. M.. Matrículas de crianças com necessidades educacionais especiais na rede de ensino regular: do que e de quem se fala? In: GÓES, M. C. R. de; LAPLANE, A. L. F. (Org.) Políticas e Práticas de Educação Inclusiva. 2. ed. Campinas, SP: Autores Associados, 2007. p. 49-68. Coleção Educação Contemporânea.

LAPLANE, A. L. F.. Notas para uma análise dos discursos sobre inclusão escolar. In: GÓES, M. C. R. de; LAPLANE, A. L. F. (Org.) Políticas e Práticas de Educação Inclusiva . Campinas, SP: Autores Associados, 2007. p. 5-20. Coleção Educação Contemporânea.

LEITE, L. P.; ARANHA, M. S. F.. Intervenção reflexiva: instrumento de formação continuada do educador especial. Psic.: Teor. e Pesq. Brasília, DF, v. 2, n. 2, p. 207-215, maio-ago. 2005. Disponivel em: <http://www.scielo.br/pdf/ptp/v21n2/ a11v21n2.pdf>. Acesso em: 6 set. 2012.

MARTINS, L. A. R. Um olhar para a formação docente na perspectiva da Educação Inclusiva. In: MARQUEZINE, M. C.; MANZINI, E. J.; BUSTO, R. M.; TANAKA, E. D. 0.; FUJISAWA, D. S. (Orgs.). Políticas Públicas e Formação de Recursos Humanos em Educação Especial. Londrina: ABPEE, 2009. p. 107-118.

MICHELS, M. H.. Gestão, formação docente e inclusão: eixos da reforma educacional brasileira que atribuem contornos à organização escolar. Rev. Bras. Educ. 2006, v.11, n. 33, p. 406-423.

MENDES, E. G. Inclusão Escolar com colaboração: unindo conhecimentos, perspectivas e habilidades profissionais. In: MARTINS, L. A. R.; PIRES, J.; PIRES, G. N. L. (Orgs.). Políticas e Práticas Educacionais Inclusivas. Natal: EDUFRN, 2009. p. 19-51. 
OLIVEIRA, A. A. S. Adequações Curriculares na área da deficiência intelectual: algumas reflexões. In: OLIVEIRA, A. A. S.; OMOTE, S.; GIROTO, C. R. M. Inclusão Escolar: as contribuições da Educação Especial. São Paulo: Cultura Acadêmica; Marília: Fundepe, 2008. p. 129-154.

Aprendizagem escolar e deficiência intelectual: a questão da avaliação curricular. In: PLETSCH, M. D.; DAMASCENO, A. (Org.). Educação Especial e inclusão escolar: reflexões sobre o fazer pedagógico desde a Educação Infantil até o Ensino Superior. Rio de Janeiro: Edur, 2011.

Currículo e deficiência intelectual: a construção de um referencial de avaliação, SP. In: Congresso Brasileiro de Educação Especial, 4., 2010, São Carlos: UFSCAR, 2010a.

. Um diálogo esquecido: a vez e a voz de adolescentes com deficiência. Londrina: Ed. Práxis, 2007.

Inclusão escolar e formação de professores: o embate entre o geral e 0 específico. In: MENDES, E. G.; ALMEIDA, M. A. (Org.). Das margens ao centro: perspectivas para as políticas e práticas educacionais no contexto da educação especial inclusiva. Araraquara: Junqueira \& Marin, 2010. p. 141-150.

Inclusão no Brasil: políticas públicas para o educando com necessidades educacionais especiais. In: GENARO, K. F.; LAMÔNICA, D. A. C.; BEVILACQUA, M. C. O processo de comunicação: contribuição para a formação de professores na inclusão de indivíduos com necessidades educacionais especiais. São José dos Campos: Ed. Pulso, 2006. p. 255-276.

A política de formação de professores para educação especial: a ausência de diretrizes ou uma política anunciada?. In: PINHO, S. Z. (Org.). Formação de educadores: o papel do educador e sua formação. São Paulo: Ed. UNESP, 2009. p. 257-271.

OLIVEIRA, A. A. S.; LEITE, L. P. Construção de um Sistema Educacional Inclusivo: um desafio político-pedagógico. Ensaio: Avaliação e Políticas Públicas em Educação. v.15, 2007. p. 511-524.

OLIVEIRA, A. M. L. A.; SIGOLO, S. R. R. L. Sala de recursos e educação inclusiva: interconexões entre contextos. In: DALL'AQUA, M. J. C.; ZANIOLO, L. O. (Org.) Educação Inclusiva em perspectiva: reflexões para formação de professores. Curitiba: Ed. CRV, 2009. p. 41-59. 
OMOTE, S. Perspectivas para conceituação de deficiências. Revista Brasileira de Educação Especial, Marília, v. 2, n. 4, 1996. p. 127-136

PACHECO, J.; EGGERTSDÓtTIR, R.; MARINÓSSON, G. L. Caminhos para a Inclusão: um guia para o aprimoramento da equipe escolar. Porto Alegre: Artmed, 2007.

PADILHA, A. M. L. Práticas pedagógicas e a inserção sócio-cultural do deficiente: a complexidade da proposta. In: MANZINI, E. J. (Org.). Inclusão e acessibilidade. Marilia: ABPEE, 2006. p. 43-50.

PIRES, J. Formação para a inclusão: a aprendizagem da construção de uma identidade inclusiva através das relações pedagógicas estabelecidas no processo formativo professor-educador. In: MARTINS, L. A. R.; PIRES, J.; PIRES, G. N. L. (Orgs.). Políticas e práticas educacionais inclusivas. Natal: EDUFRN, 2009. p. 53-72.

PLESTCH, M. D. Repensando a inclusão escolar: diretrizes políticas, práticas curriculares e deficiência intelectual. Rio de Janeiro: Nau; Edur, 2010.

PRIETO, R. G. Professores Especializados de um centro de apoio: estudo sobre saberes necessários para sua prática. In: JESUS, D. M.; BAPTISTA, C. R.; BARRETO, M. A. S. C.; VICTOR, S. L. (Org.). Inclusão, práticas pedagógicas e trajetórias de pesquisa. Porto Alegre: Mediação, 2007. p. 281-294.

. Educação inclusiva com ênfase no atendimento de alunos com necessidades educacionais especiais: qual formação de professores? In: PINHO, S. Z. (Org.). Formação de educadores: o papel do educador e sua formação. São Paulo: Ed. UNESP, 2009. p. 273-287.

POKER, R. B. Adequações Curriculares na área da surdez. In: OLIVEIRA, A. A. S.; OMOTE, S.; GIROTO, C. R. M. Inclusão escolar: as contribuições da Educação Especial. São Paulo: Cultura Acadêmica; Marília: Fundepe, 2008. p.167-178.

SÃO PAULO (Municipio). Secretária Municipal de Educação. Decreto nº 33.891, de 16 de dezembro de 1993. Dispõe sobre a politica de atendimento aos portadores de necessidades especiais na Rede municipal de ensino. São Paulo, 17 dez. 1993. Disponivel em < http:// camaramunicipalsp.qaplaweb.com.br/iah/fulltext/decretos/D33891.pdf>. Acesso em: 6 set. 2012. 
SÃO PAULO (Município). Secretaria Municipal de Educação. Diretoria de Orientação Técnica. Decreto n. 45.415, de 18 de outubro de 2004. Dispõe de politica de atendimento a crianças, adolescentes, jovens e adultos com necessidades educacionais especiais no sistema municipal de ensino. São Paulo, 18 out. 2004. Disponivel em: <http://portalsme.prefeitura.sp.gov.br/Documentos/ BibliPed/TextosLegais/LegislacaoEducacional/DecretoMunicipal_45415.pdf>. Acesso em: 06 set. 2012.

. Secretaria Municipal de Educação. Diretoria de Orientação Técnica. Referencial sobre Avaliação da Aprendizagem na área da Deficiência Intelectual. São Paulo: SME / DOT, 2008.

Secretaria Municipal de Educação. Portaria n. 2755/09, de 23 de novembro de 2010. Dispõe sobre a realização de cooperação ou parcerias entre entidades sem fins lucrativos para o desenvolvimento e a execução dos programas de aprendizagem, nos termos do art. 430 da Consolidação das Leis do Trabalho - CLT. São Paulo: SME, 11 maio 2009. Disponivel em: <http:// www81.dataprev.gov.br/sislex/paginas/63/MTE/2010/2755.htm>. Acesso em: 06 de set. 2012.

. Secretaria Municipal de Educação. Relatório da Comissão Especial de Trabalho. São Paulo: Mimeografado, 2010.

SEBASTIÁN HEREDERO, E. A la calidad de la educación desde los espacios escolares: visión del profesorado y perpstivas en la educación castellanomachega. Universidad de Alcalá de Henares: España, 2008. 344 p.

SIGOLO, A. R. L.; GUERREIRO, E. M. B. R.; CRUZ, A. R. S. Políticas educacionais para a Educação Especial no Brasil: uma breve contextualização histórica. Práxis, Ponta Grossa, v. 5, n. 2, p. 173-194, jul./dez. 2010.

STAINBACK, S.; STAINBACK, W. Inclusão: um guia para educadores. Porto Alegre: Artmed, 1999.

SOUSA, S. M. Z. L.; PRIETO, R. G. Revista Brasileira de Educação Especial, v.7, n.1, 2001.

VALENTIM. F. O. D. Inclusão de alunos com deficiência intelectual: considerações sobre avaliação da aprendizagem escolar. 2011. 132 f. Dissertação. (Mestrado) Programa de Pós-graduação em Filosofia e Ciências, Faculdade de Filosofia e Ciências, Universidade Estadual Paulista, Marília, 2011. 